\title{
A Call to Action: Reinvigorating Interest and Investments in Health Infrastructure
}

\author{
Lindsay M. Mallick, ${ }^{a, b, c}$ Joshua Amo-Adjei ${ }^{d}$
}

\section{See related article by Rokicki et al.}

$\mathbf{P}$ erson-centered care and measurement of the client experience has captured the spotlight in the field of quality of care, ${ }^{1}$ especially amidst growing awareness of pervasive mistreatment and disrespectful care. ${ }^{2,3}$ Despite the importance of this topic, a focus on strengthening infrastructure cannot fall by the wayside. In this issue of GHSP, Rokicki et al. draw our attention to structural aspects of delivery care and demonstrate their importance in health care delivery. ${ }^{4}$

In essence, infrastructure is essential for high-quality care, yet improvements in health infrastructure in lowand middle-income countries (LMICs) have not progressed on pace with the increasing demand for health services, especially in sub-Saharan Africa. ${ }^{5}$ A renewed focus on infrastructure to both improve health and protect and retain the health care workforce-a focus that works in tandem with efforts to promote person-centered care, is environmentally friendly, and aims to equip facilities to handle infectious disease outbreaks-is direly needed. Here, we make the plea to reinvigorate interest and investments in health infrastructure.

\section{QUALITY CANNOT OCCUR IN THE ABSENCE OF ADEQUATE INFRASTRUCTURE}

In the past several decades, we have seen a dramatic increase in the use of health care facilities, especially for childbirth in LMICs, but the investments in improving access and use of services have not yielded expected decreases in maternal and newborn deaths. ${ }^{6,7}$ As Rokicki et al. mention, ${ }^{4}$ lack of high-quality care for many common, treatable conditions currently contributes to more excess deaths than lack of use of health care facilities, ${ }^{8}$ thus warranting further examination of health systems and quality of care.

Quality of care is a multidimensional construct that encompasses a spectrum of inputs and processes integral

\footnotetext{
a Department of Family Science, Maternal and Child Health Program, School of Public Health, University of Maryland, College Park, MD, USA.

${ }^{b}$ Maryland Population Research Center, College Park, MD, USA

${ }^{c}$ Avenir Health, Glastonbury, CT, USA

'University of Cape Coast, Cape Coast, Ghana.

Correspondence to Lindsay Mallick (lindsay.mallick@gmail.com)
}

for achieving optimal health and satisfaction with care. Infrastructure-namely, electricity, water, equipment, and physical resources - along with medicines and human resources, is the most basic, foundational requirement of quality of care. These elements, which together constitute readiness for care," are "nonnegotiables" for providing health services; protecting clients and providers; and avoiding preventable infections, illness, and death. ${ }^{10}$ The Figure depicts a hierarchical structure in which we envision the cross-section of various quality of care frameworks, ${ }^{11-14}$ wherein infrastructure is at the base of the pyramid of quality health care upon which other aspects of quality and optimal health outcomes rest.

While infrastructure is critical for high-quality care, it is not a measure of services provided, ${ }^{14}$ and inadequate service provision can occur even amidst sufficient infrastructure and resources. ${ }^{15}$ Yet, the inverse does not hold, and this cannot be overemphasized. Care cannot be safe without clean water and access to sanitation, it cannot be effective without light and necessary equipment, equitable when rural facilities are most poorly prepared, timely without nearby lifesaving surgical theaters or transportation to access them, and patient-centered without attentive and skilled providers.

\section{INFRASTRUCTURE IS A REQUIREMENT FOR ADEQUATE PERSON-CENTERED CARE}

Infrastructure that allows for adherence to medical standards is a requirement for person-centered care. Personcentered care entails establishing (adult) clients as partners in their care, and through that, trust in the health care system. But without reliable energy, adequate water, and sanitation, and other vital components of health system infrastructure, clients' health and trust are in jeopardy. When these aspects of care are unavailable, it poses a risk to health, further undermines trust, deters future care seeking, and worsens health outcomes. ${ }^{10}$

\section{HUMAN RESOURCE PROTECTION AND RETENTION THROUGH INFRASTRUCTURE INVESTMENT}

Even more important when considering the deleterious impact of the coronavirus disease (COVID-19) pandemic 


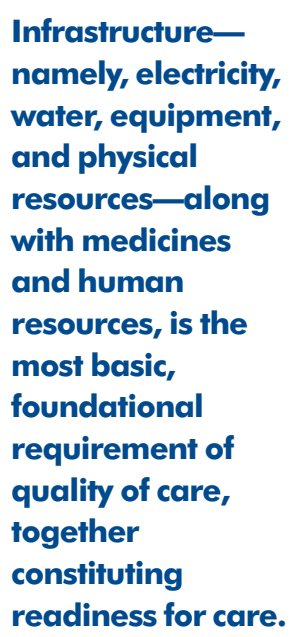

FIGURE. Hierarchy of Quality of Care ${ }^{a}$

Care resulting in patient health, satisfaction, future care seeking

Experience of respectful and person-centered care

Provision of effective, efficient, equitable care

Provision of safe care in sanitary conditions

Adequate infrastructure and resources

This figure depicts an integration of components of quality of care based on various frameworks, ${ }^{11-14}$ organized into a hierarchical structure.

on human resources, adequate infrastructure protects health care workers and is associated with provider satisfaction, recruitment, and retention of the workforce. ${ }^{16-18}$ Water, sanitation, ventilation, and sharps (e.g., needles) control are necessary for infection prevention and control. Health care workers stationed at facilities without sufficient infrastructure are risking their own health to care for communities and provide suboptimal care for their patients. The lack of infrastructure, most pronounced in rural communities, is a reason often cited for poor retention of health care workers, ${ }^{16-18}$ especially when their services can be provided more lucratively in environments safer for both clients and staff. Thus, where human resources are sparse, basic infrastructure must be prioritized to acquire, protect, and retain staff.

\section{Where human resources are sparse, basic infrastructure must be prioritized to acquire, protect, and retain staff.}

\section{ADEQUATE ENERGY, WATER, HYGIENE, AND SANITATION WILL SAVE LIVES}

With high-quality care and appropriate labor and delivery management, which is contingent on having adequate health infrastructure, an estimated 1.3 million fetal, neonatal, and maternal lives can be saved by 2030 in the 75 countries where nearly all respective deaths occur. ${ }^{19}$ Rokicki et al. ${ }^{4}$ demonstrated that solar electric installation was associated with certain improvements in quality of care, specifically related to infection control, postpartum hemorrhage prevention, and newborn care, which are keystones for mortality prevention.

Electricity, either renewable or grid-powered, is also vital for lighting, medical equipment, refrigeration for preserving medicines and vaccines, ventilation, heating for sterilization, air, or water, and communication systems for record keeping, reporting, and referral processes, ${ }^{20,21}$ yet more than half of health facilities among 78 African, Asian, and Oceanic LMICs lack access to reliable electricity. ${ }^{22}$ When electricity is available, it is often unreliable, as found in $60 \%$ of the facilities in the 78 countries studied. Outages can also be chronic and enduring; for example, Ghana experienced a multiyear power crisis between 2012 and 2016, where electricity was unstable throughout the entire country. These frequent and prolonged power outages were detrimental for the health care system; one study found that the risk of mortality in facilities in Ghana increased by $43 \%$ when power was out for more than 2 hours. ${ }^{23}$

There are risks and consequences of seeking care in facilities without adequate water, sanitation, and hygiene (WASH) structures, yet the statistics for the availability of WASH are grimmer than those statistics for electricity. In those same 78 LMICs, only two-thirds of health facilities had improved toilets, 3 of 5 had soap, and half had piped water; worse, only $2 \%$ had all 4 : toilets, soap, water, and waste management. ${ }^{22}$ The World Health Organization (WHO)/United Nations Children's 
Fund (UNICEF) Joint Monitoring Programme for WASH estimates that this translates to 900 million people accessing health care facilities without water and 1.5 billion without sanitation services. ${ }^{24}$ Although hospital or facility-acquired infections during birth are largely preventable through tetanus vaccination and clean birth practices (e.g., handwashing and sanitary umbilical cord care), infection acquired during this time is a leading cause of death for mothers and babies. ${ }^{25,26}$ There is also an increased risk of developing antimicrobial resistance when clients are exposed to human waste (which carries antimicrobial-resistant pathogens) in health care facilities that lack improved toilets or have poor sanitation systems. ${ }^{24}$

\section{口 INFRASTRUCTURE NEEDS DURING COVID-19}

The COVID-19 pandemic has revealed additional health care system gaps that are essential for managing infectious respiratory diseases such as severe acute respiratory syndrome coronavirus 2 (SARSCoV-2). Recently, the Demographic and Health Surveys Program highlighted limited readiness to manage infectious diseases according to Service Provision Assessment surveys conducted in health facilities across 3 regions of the Global South. Between 1 to 6 in 10 facilities have communication equipment (a landline, facility-owned, or supported private cellular phone or a short-wave radio $)^{27}$ necessary to refer patients to higher-level facilities for intensive or specialist care and coordinating supportive therapy with oxygen. Although a lack of data is a barrier to assessing oxygen needs more broadly, ${ }^{28}$ only $16 \%$ or less of facilities in 7 countries with recent Service Provision Assessment surveys reported availability of oxygen. ${ }^{27}$ However, efforts to scale up oxygen are underway, $^{28}$ and the WHO COVID-19 Essential Supplies Forecasting Tool (https://apps.who.int/ iris/rest/bitstreams/1342089/retrieve) can help to estimate needs for oxygen and other equipment, supplies, and drugs for care and treatment of COVID-19. In addition, recommen-dations for managing patient oxygen needs in resourceconstrained settings are compiled and summarized by Serpa Neto et al. ${ }^{29}$

For reducing transmission in health care facilities, adequate air filtration and ventilation are paramount $^{30,31}$ alongside management of patient flow and personal protective equipment for health care workers. The increased use of intensive care units in the face of COVID-19 further stresses the need for health infrastructure. In intensive care units especially, adequate heating, ventilation, and air conditioning systems are central to maintaining positive pressure or negative pressure rooms to reduce the spread of airborne pathogens. ${ }^{32}$ High-efficiency particulate air filtration or negative pressure zones can reduce the risk of spread of infections in intensive care units, operating rooms, or other areas where procedures generate aerosolized particles. ${ }^{32,33}$ In resourceconstrained settings, these systems are limited given their requirement for stable electricity; however, health care administrators can also use several strategies to limit spread including using personal protective equipment, triaging patients to evaluate urgency, postponing nonemergent procedures, screening and testing for COVID-19, and isolating COVID-19 positive or suspected cases. ${ }^{34,35}$ These recommendations and others are detailed in the WHO's Maintaining Essential Health Services: Operational Guidance for the COVID-19 Context. ${ }^{35}$

As shown by Our World in Data (https:// ourworldindata.org/covid-vaccinations), as of December 2021 , only $6 \%$ of the population in lowincome countries had been vaccinated, compared with $74 \%$ in high-income countries. The disparate rollout of vaccines against SARS-CoV-2 relates both to vaccine equity - the sharing of vaccines and technology-as well as infrastructure-related challenges in the vaccine cold chain, wherein vaccines must be maintained below or near-freezing temperatures (with temperature variation across different vaccines) from manufacturer to distribution sites. ${ }^{36}$ This is particularly problematic in areas that are rural, lack road infrastructure, are susceptible to transportation barriers during wet seasons, or have facilities that lack electricity for storage. ${ }^{36}$ In 2016, Gavi, the Vaccine Alliance (the organization largely responsible for COVID-19 vaccine rollout in LMICs through COVAX), established the Cold Chain Equipment Optimization Platform, which can be used to plan investments to ensure maintenance of cold chains and, ultimately, improve coverage. ${ }^{37}$ A scale-up of these cold chain management and other vaccine efforts are essential to reduce the burden of COVID; without these, COVID-19 will likely remain endemic, ${ }^{36}$ with a persisting cycle of mutations of new variants.

\section{CLIMATE-FRIENDLY AND CLIMATE- RESISTANT ENERGY, WATER, AND SANITATION SOLUTIONS}

It is most responsible to plan for improvements in infrastructure by considering their environmental impacts. Further, the reality of climate change is such that new installations must be robust

\section{The reality of climate change is such that improvements in infrastructure must be robust to endure extreme and worsening weather conditions.}


to endure extreme and worsening weather conditions. While these installations may require substantial initial investments, they have the benefit of lowering longterm operation costs, reducing health care costs, and yielding an overall cost savings. ${ }^{10,38,39}$

How countries should invest in energy should be determined based on available resources and careful examination of the feasibility and costeffectiveness of renewable energy versus conventional, grid-powered energy. Renewable or hybrid renewable systems that draw from multiple sources of renewable energy, including wind and solar energy, can deliver sustainable, reliable, environmentally friendly methods of powering basic equipment at health care facilities and have been proposed to meet demands in both urban and rural areas. $^{21,40}$ The Hybrid Optimization Model for Electric Renewables software (owned by UL), for example, can assist with planning such investments through techno-economic simulations that take into account geographic-specific information. ${ }^{21,40}$

To improve WASH in health care facilities, the WHO outlines 8 practical steps, including conducting assessments, establishing goals and standards, investing in infrastructure, monitoring WASH systems, training health care workers, engaging communities, and conducting further research. ${ }^{41}$ Recently, UNICEF has supported using wind and solar-powered water pumping systems, that while requiring substantial up-front costs, are environmentally friendly, climate-resistant, and have long-term cost payoffs. ${ }^{39}$ UNICEF details programmatic approaches for improving access to water, including collaboration with climate-sector actors and consideration of local needs and resources. ${ }^{38}$

Among other climate-friendly suggestions for waste management, the WHO recommends consideration of steam-based methods over incineration for decontamination of infectious waste to prevent any further environmental harm. ${ }^{10}$ Moat and Lavis provide an additional resource for developing evidenceinformed policies that can be broadly applied to consider other aspects of infrastructure development. ${ }^{42}$

\section{- INFRASTRUCTURE INVESTMENT FOR THE GREATEST GAINS}

To be sure, investments in infrastructure for health can be costly and seem untenable in resourceconstrained settings. These investments compete with other equally important areas. Nonetheless, infrastructure investments can contribute substantially to alleviating burdens of morbidity and mortality while also providing a positive return on investment in the long term. ${ }^{10}$
In summary, advocacy for better infrastructure must continue until facilities are equipped to handle the health issues they face. Although providing poor quality of care pervades even the most wellequipped service environments, high-quality care is only possible in settings where key infrastructure requirements are met. Any new infrastructure investments should consider environmentally friendly options durable to the extreme weather conditions resulting from climate change, while also bolstering readiness requirements for current and future infectious disease outbreaks. Future human resources, client care-seeking behaviors, and optimal health outcomes depend on these investments.

Competing interests: None declared.

\section{REFERENCES}

1. Rubashkin N, Warnock R, Diamond-Smith N. A systematic review of person-centered care interventions to improve quality of facilitybased delivery. Reprod Health. 2018;15(1):169. CrossRef. Medline

2. Bowser D, Hill K. Exploring Evidence for Disrespect and Abuse in Facility-Based Childbirth: Report of a Landscape Analysis. USAIDTRAction Project, Harvard School of Public Health; 2010. Accessed November 19, 2021. https://cdn 1.sph.harvard.edu/wp-content/ uploads/sites/2413/2014/05/Exploring-Evidence-RMC_Bowser_ rep_2010.pdf

3. Bohren MA, Mehrtash H, Fawole B, et al. How women are treated during facility-based childbirth in four countries: a cross-sectional study with labour observations and community-based surveys. Lancet. 2019;394(10210):1750-1763. CrossRef. Medline

4. Rokicki S, Mwesigwa B, Waiswa P, Cohen J. Impact of solar light and electricity on the quality and timeliness of maternity care: a steppedwedge cluster randomized trial in Uganda. Glob Health Sci Pract. 2022;9(4). CrossRef

5. Calderon C, Cantu C, Chuhan-Pole P. Infrastructure Development in Sub-Saharan Africa: A Scorecard. World Bank; 2018. Accessed November 19, 2021. https://openknowledge.worldbank.org/ bitstream/handle/10986/29770/Infrastructure-development-inSub-Saharan-Africa-a-scorecard.pdf? sequence=5\&isAllowed=y

6. Hurst TE, Semrau K, Panna M, Gawande A, Hirschhorn LR. Demand-side interventions for maternal care: evidence of more use, not better outcomes. BMC Pregnancy Childbirth. 2015;15(1):297. CrossRef. Medline

7. Winter R, Pullum T, Florey L, Hodgins S. Impact of scale-up of maternal and delivery care on reductions in neonatal mortality in USAID MCH priority countries, 2000-2010. In: Applied Demography and Public Health in the 21 st Century. Springer; 2017:269-305

8. Kruk ME, Gage AD, Joseph NT, Danaei G, García-Saisó S, Salomon JA. Mortality due to low-quality health systems in the universal health coverage era: a systematic analysis of amenable deaths in 137 countries. Lancet. 2018;392(10160):2203-2212. CrossRef. Medline

9. Service availability and readiness assessment (SARA). World Health Organization. Accessed November 19, 2021. https://www. who. $\mathrm{int} /$ data/data-collection-tools/service-availability-and-readinessassessment-(sara)? $\mathrm{ua}=1$

10. World Health Organization (WHO). Global Progress Report on Water, Sanitation and Hygiene in Health Care Facilities: Fundamentals First. WHO; 2020. Accessed November 19, 2021. https://www.who.int/publications/i/item/9789240017542

11. Donabedian A. The quality of care. How can it be assessed? JAMA. 1988;260(12):1743-1748. CrossRef. Medline

12. Donabedian A. Evaluating the quality of medical care. Milbank Mem Fund Q. 1966;44(3):166-206. CrossRef. Medline 
13. Tunçalp Ö, Were WM, MacLennan C, et al. Quality of care for pregnant women and newborns - the WHO vision. BJOG. 2015;122(8):1045-1049. CrossRef. Medline

14. Kruk ME, Gage AD, Arsenault C, et al. High-quality health systems in the Sustainable Development Goals era: time for a revolution. Lancet Glob Health. 2018;6(11):e1 196-e1252. CrossRef. Medline

15. Leslie HH, Sun Z, Kruk ME. Association between infrastructure and observed quality of care in 4 healthcare senvices: a cross-sectional study of 4,300 facilities in 8 countries. PLoS Med. 2017;14(12): e1002464. CrossRef. Medline

16. Fejfar D, Guo A, Kelly E, Tidwell JB, Ochieng O, Cronk R. Healthcare provider satisfaction with environmental conditions in rural healthcare facilities of 14 low- and middle-income countries. Int J Hyg Environ Health. 2021;236:113802. CrossRef. Medline

17. Ojakaa D, Olango S, Jarvis J. Factors affecting motivation and retention of primary health care workers in three disparate regions in Kenya. Hum Resour Health. 2014;12(1):33. CrossRef. Medline

18. Essendi H, Johnson FA, Madise N, et al. Infrastructural challenges to better health in maternity facilities in rural Kenya: community and healthworker perceptions. Reprod Health. 2015;12(1):103. CrossRef. Medline

19. Marchant T, Bryce J, Victora C, et al. Improved measurement for mothers, newborns and children in the era of the Sustainable Development Goals. J Glob Health. 2016;6(1):010506-010506. CrossRef. Medline

20. Castán Broto V, Kirshner J. Energy access is needed to maintain health during pandemics. Nat Energy. 2020;5(6):419-421. CrossRef

21. Olatomiwa L, Blanchard R, Mekhilef S, Akinyele D. Hybrid renewable energy supply for rural healthcare facilities: an approach to quality healthcare delivery. Sustainable Energy Technologies Assessments. 2018;30:121-138. CrossRef

22. Cronk R, Bartram J. Environmental conditions in health care facilities in low- and middle-income countries: coverage and inequalities. Int $J$ Hyg Environ Health. 2018;221(3):409-422. CrossRef. Medline

23. Apenteng BA, Opoku ST, Ansong D, Akowuah EA, Afriyie-Gyawu $E$. The effect of power outages on in-facility mortality in healthcare facilities: evidence from Ghana. Glob Public Health. 2018;13 (5):545-555. CrossRef. Medline

24. World Health Organization (WHO), United Nations Children's Fund (UNICEF). WASH in Health Care Facilities: Global Baseline Report 2019. WHO, UNICEF; 2019. Accessed November 19, 2021. https://www.unwater.org/publications/wash-in-health-carefacilities-global-baseline-report-2019/

25. Say L, Chou D, Gemmill A, et al. Global causes of maternal death: a WHO systematic analysis. Lancet Glob Health. 2014;2(6):e323e333. CrossRef. Medline

26. Blencowe H, Cousens S, Mullany LC, et al. Clean birth and postnatal care practices to reduce neonatal deaths from sepsis and tetanus: a systematic review and Delphi estimation of mortality effect. BMC Public Health. 2011;11(3)(Suppl 3):S1 1. CrossRef. Medline

27. The DHS Program. Infection Control and Readiness in Health Facilities Data From Service Provision Assessment (SPA) Surveys. U.S. Agency for International Development; 2020. Accessed November 19, 2021. https://dhsprogram.com/pubs/pdf/OF46/ OF46.pdf
28. World Health Organization (WHO). WHO Technical Consultation on Oxygen Access Scale-up for COVID-19. WHO; 2021. Accessed November 19, 2021. https://apps.who.int/iris/bitstream/handle/ 10665/342817/9789240031517-eng.pdf? sequence=1

29. Serpa Neto A, Checkley W, Sivakorn C, et al. Pragmatic recommendations for the management of acute respiratory failure and mechanical ventilation in patients with COVID-19 in low- and middle-income countries. Am J Trop Med Hyg. 104(3 Suppl):60-71. CrossRef. Medline

30. Allen JG, Ibrahim AM. Indoor air changes and potential implications for SARS-CoV-2 transmission. JAMA. 2021;325(20):2112-2113. CrossRef. Medline

31. Ghaffari HR, Farshidi $\mathrm{H}$, Alipour V, et al. Detection of SARS-CoV-2 in the indoor air of intensive care unit (ICU) for severe COVID-19 patients and its surroundings: considering the role of environmental conditions. Environ Sci Pollut Res Int. $2021 ; 1-7$. CrossRef. Medline

32. Saran S, Gurjar M, Baronia A, et al. Heating, ventilation and air conditioning (HVAC) in intensive care unit. Crit Care. 2020;24 (1):194. CrossRef. Medline

33. Mendelson $M$, Booyens $L$, Boutall A, et al. The mechanics of setting up a COVID-19 response: experiences of the COVID-19 epidemic from Groote Schuur Hospital, Cape Town, South Africa. S Afr Med J. 2020;1 10(10):968-972. CrossRef. Medline

34. White DB, Lo B. Mitigating inequities and saving lives with ICU triage during the COVID-19 pandemic. Am J Respir Crit Care Med. $2021 ; 203(3): 287-295$. CrossRef. Medline

35. World Health Organization (WHO). Maintaining Essential Health Services: Operational Guidance for the COVID-19 Context: Interim Guidance. WHO; 2020. Accessed November 19, 2021. https:// apps.who.int/iris/handle/10665/332240

36. Acharya KP, Ghimire TR, Subramanya SH. Access to and equitable distribution of COVID-19 vaccine in low-income countries. NPJ Vaccines. $2021 ; 6(1): 54$. CrossRef. Medline

37. Gavi, the Vaccine Alliance. Cold Chain Equipment Optimization Platform (CCEOP). Gavi; 2020. Accessed November 19, 2021. https://www.gavi.org/sites/default/files/publications/Cold-chainequipment-technology-guide.pdf

38. United Nations Children's Fund (UNICEF). UNICEF Guidance Note: Programmatic Approaches to Water Scarcity. UNICEF; 2021 Accessed November 19, 2021. https://www.unicef.org/media/ 95341 /file/UNICEF\%20guidance\%20note\%20programmatic\% 20 approaches\%20to\%20water\%20scarcity.pdf

39. United Nations Children's Fund (UNICEF). Reimagining WASH: Water Security for All. UNICEF; 2021. Accessed November 19, 2021. https:// wuw.unicef.org/media/95241/file/water-security-for-all.pdf

40. Bahramara S, Moghaddam MP, Haghifam MR. Optimal planning of hybrid renewable energy systems using HOMER: a review. Renew Sustain Energy Rev. 2016;62:609-620. CrossRef

41. World Health Organization (WHO). Water, Sanitation and Hygiene in Health Care Facilities: Practical Steps to Achieve Universal Access to Quality Care. WHO; 2019. Accessed November 19, 2021 https://www.who.int/publications/i/item/978924151551 1

42. Moat KA, Lavis JN. 10 best resources for ... evidence-informed health policy making. Health Policy Plan. 2013;28(2):215-218. CrossRef. Medline

Received: October 11, 2020; Accepted: November 16, 2021; First published online: December 9, 2021.

Cite this article as: Mallick LM, Amo-Adjei J. A call to action: reinvigorating interest and investment in health infrastructure. Glob Health Sci Pract. 2021;9(4):711-715. https://doi.org/10.9745/GHSP-D-21-00674

(C) Mallick and Amo-Adjei. This is an open-access article distributed under the terms of the Creative Commons Attribution 4.0 International License (CC BY 4.0), which permits unrestricted use, distribution, and reproduction in any medium, provided the original author and source are properly cited. To view a copy of the license, visit https://creativecommons.org/licenses/by/4.0/. When linking to this article, please use the following permanent link: https://doi.org/10.9745/GHSP-D-21-00674 